\title{
RELAÇÃO ENTRE A QUALIDADE DA PAISAGEM E O RISCO DE INCÊNDIOS FLORESTAIS
}

\author{
José Renato Soares Nunes*, Alexandre Beutling**, Letícia de Paulo Koproski***, \\ Luiz Antonio Nunes de Melo****, Daniela Biondi*****, Antonio Carlos Batista* \\ *Eng. Florestal, Dr., Depto. de Ciências Florestais, UFPR - zerenato@floresta.ufpr.br - batistaufpr@ufpr.br \\ **Eng. Florestal, M.Sc., Doutorando em Engenharia Florestal, UFPR - ale_jeep@floresta.ufpr.br \\ ***Veterinária, M.Sc., Doutoranda em Engenharia Florestal, UFPR - leticia@floresta.ufpr.br \\ ****Eng. Florestal, M.Sc., Ibama - nunesdemelo@uol.com.br \\ *****Enga . Florestal, Dr ${ }^{\mathrm{a}}$., Depto. de Ciências Florestais, UFPR - dbiondi@ufpr.br
}

Recebido para publicação: 17/08/2006 - Aceito para publicação: 13/07/2007

\begin{abstract}
Resumo
A qualidade de uma paisagem é um atributo intrínseco de um território. A fragilidade depende do tipo de atividade que se desenvolve nesse território. Regiões com baixo valor paisagístico podem apresentar condições que favoreçam a propagação de incêndios, em função das características do material combustível oriundas da cobertura vegetal, relevo e condições meteorológicas. Uma paisagem degradada é um ambiente frágil, podendo permitir a ação de agentes externos, como a erosão, as pragas e o fogo. O objetivo deste trabalho foi buscar uma relação entre a qualidade da paisagem e o risco de incêndios florestais, usando métodos de valoração da qualidade e da fragilidade da paisagem, baseados em mapas descritivos de uma região. A área estudada foi a Fazenda Brejão, propriedade da Empresa Vallourec \& Mannesmann, localizada em Brasilândia, Minas Gerais. Os resultados indicam boa correlação entre a qualidade da paisagem e o risco de incêndios florestais, sugerindo que a valoração da qualidade da paisagem pode ser uma ferramenta importante para o zoneamento do risco de incêndios.

Palavras-chave: Fragilidade da paisagem; valoração da paisagem; zoneamento de risco.
\end{abstract}

\begin{abstract}
Relationship between landscape quality and forest fire risk. The landscape quality is an intrinsic attribute of a territory. The fragility of the landscape depends on the type of activity developed in this territory. Regions with low landscape quality can present conditions that favor the fire spread, in function of the forest fuel, existing vegetal covering and characteristics of meteorological conditions. A degraded landscape is a fragile environment, being able to allow the action of external agents as the erosion, the plagues and forest fires. The objective of this work was to search a relation between landscape quality and forest fire risk, using methods of landscape quality and fragility evaluation, based on descriptive maps of a region. The studied area was the Brejão Farm, property of the Company Vallourec \& Mannesmann, located in Brasilândia, Minas Gerais state. The results indicate a good correlation between the landscape quality and the forest fire risk, suggesting that the landscape quality can be an important tool for the refinement and zoning of the fire risk.

Keywords: Landscape fragility; landscape valuation; mapping.
\end{abstract}

\section{INTRODUÇÃO}

A paisagem é fruto da interação dos componentes geológicos expostos à ação do clima, fatores geomorfológicos, bióticos e antrópicos através do tempo. Encontra-se em constante evolução, podendo a sua estrutura e composição mudar drasticamente (ROCHA, 1995). O componente que está presente em todo tipo de paisagem é o tempo, que age num determinado espaço físico, com predominância de certos elementos, para formar os diversos tipos de paisagens, como paisagem urbana, paisagem litorânea, paisagem florestal, etc. Outros fatores eventuais também são responsáveis pela modificação da paisagem ao longo do tempo, como, por exemplo, furacões, tempestades, incêndios, pragas, doenças, vulcões, enchentes, secas e poluição (BIONDI; LEAL, 2002). A paisagem pode ser recuperada, manejada ou 
transformada em outro tipo, conforme a intervenção humana e/ou a exuberância natural da paisagem (BIONDI, 2000).

A valoração da qualidade visual da paisagem pode ser realizada em função do valor estético e ambiental dos seus elementos ou do seu conjunto como um todo (CANTERAS JORDANA, 1992). A problemática da paisagem, expressa como qualidade da paisagem, tem sido abordada de diversas formas por profissionais encarregados de sua avaliação, fazendo surgir múltiplos métodos (ALVAREZALFONSO, 1990).

De acordo com Aguilo (1984), Gonzalez Bernaldez (1981), Alonso et al. (1983), Escribano (1989) e Alvarez-Alfonso (1990), os métodos mais utilizados para a valoração da paisagem podem ser resumidos da seguinte forma: método direto - a valoração se realiza a partir da contemplação da totalidade da paisagem; método indireto - a valoração se realiza através da análise dos componentes da paisagem, com ou sem ponderação e avaliação estatística; e método misto - faz-se inicialmente uma valoração direta e depois uma análise dos componentes, para averiguar a participação de cada um deles no valor total da paisagem.

Pires (1993), aplicando o método indireto de avaliação da qualidade visual da paisagem da região carbonífera de Criciúma (SC), concluiu que o critério do juízo de valor possibilita a livre escolha das variáveis e dos critérios de avaliação para cada um dos componentes básicos com os quais a paisagem deve ser analisada. Isso só é possível depois de conhecidas as limitações determinadas pelas características territoriais, disponibilidade e qualidade dos dados a serem utilizados.

Marenzi (1996) concluiu que a aplicação do método misto e da análise de regressão linear múltipla para a valoração da paisagem e preferências paisagísticas no município da Penha (SC) serviu para discriminar a importância das variáveis ambientais e atributos paisagísticos da região, possibilitando trabalhar com as informações separadas em categorias ou grupos e unidades de paisagem.

Hardt (2000) constatou, através da valoração da paisagem urbana de Curitiba, que os procedimentos de base estritamente técnica (método direto) apresentam variações de resultados em relação ao estudo da experiência humana, oriundo da observação de preferências visuais (método direto) e da sua interpretação por análise de regressão (método misto). Sendo assim, os métodos de avaliação da qualidade da paisagem não são excludentes entre si: é necessária a integração de diversas metodologias de valoração paisagística para agregar os valores intrínsecos do ambiente, a experiência humana e a subjetividade dos observadores da paisagem.

A capacidade paisagística de um determinado local pode ser entendida como a soma de suas potencialidades, os atributos naturais; qualidades, valoração dos componentes mais importantes para a sua existência e; fragilidades, grau de susceptibilidade de seus atributos à deterioração quando submetidos a uma ação natural ou artificial do meio (CANTERAS, 1992; BOLOS y CAPDEVILA, 1992).

É possível que exista uma relação entre a capacidade paisagística de uma região e a sua vulnerabilidade à ação de agentes externos, entre as quais, o risco de incêndio. Áreas ou regiões com baixo valor paisagístico podem apresentar condições que favoreçam a propagação de incêndios, em função das características do material combustível oriundo da cobertura vegetal existente, da topografia e das condições meteorológicas. Além do mais, a predisposição a incêndios pode estar relacionada à probabilidade do fogo iniciar pela presença e/ou atividades antrópicas, que são também fatores que influenciam a fragilidade do ambiente.

De acordo com Cheney (1968), perigo de incêndio (fire danger) pode ser definido como "um termo geral que expressa o resultado dos fatores constantes e variáveis, que afetam as chances de um incêndio iniciar, propagar e provocar danos, e a dificuldade de controlá-lo".

Segundo Brown; Davis (1973), o perigo de incêndio (fire danger) está relacionado ao material combustível definido pelo tipo, arranjo, quantidade, condição e localização, formando uma condição especial de ameaça de ignição. O risco de incêndio (fire risk) está relacionado à probabilidade do fogo iniciar pela presença e/ou atividade de agentes causadores.

De acordo com Macedo; Sardinha (1987), vulnerabilidade se refere aos combustíveis e às condições ambientais que tornam os combustíveis suscetíveis de ignição. O conceito de risco se refere ao perigo de eclosão dos incêndios.

Segundo Castañeda (1997), o risco de incêndio é composto pela vulnerabilidade e pelo fator de ameaça a que está submetido o ambiente. A vulnerabilidade depende do material combustível, da topografia, das condições climáticas e do tipo de solo. $\mathrm{O}$ fator de ameaça diz respeito à existência de 
agentes naturais e antrópicos que dão início ao processo de combustão.

Segundo Oliveira (2002), o risco de incêndio depende de variáveis que podem influir tanto na disponibilidade da fonte de fogo para o seu início como nas condições que favorecem a sua propagação, como o tipo de vegetação, as características do material combustível, a topografia e as condições meteorológicas.

Segundo Soares (1972a), índices de perigo de incêndio são números que refletem, antecipadamente, a probabilidade de ocorrer um incêndio, assim como a facilidade do mesmo se propagar, com base nas condições atmosféricas do dia ou de uma seqüência de dias. Soares (1972b) e outros autores referem-se a uma escala adjetiva para informação ao público, com graus de perigo que podem ser: Nulo, Moderado, Alto, Muito Alto e Extremo.

O tipo de cobertura vegetal exerce acentuada influência no microclima local. Uma floresta densa e fechada intercepta a radiação solar, reduzindo a temperatura do ar e do material combustível no seu interior. Ela também funciona como uma barreira, evitando a livre passagem de correntes de ar, reduzindo a velocidade do vento em seu interior. Isso diminui a evaporação, dificultando a secagem do material combustível. Além disso, a transpiração do material florestal proporciona um aumento da umidade relativa do ar na área da floresta. Todos esses fatores reunidos podem reduzir o risco de ignição e propagação de incêndios em uma floresta com essas características (SCHROEDER; BUCK, 1970; BROWN; DAVIS, 1973; PYNE, 1984; SOARES, 1985).

Uma paisagem degradada é um ambiente frágil, que pode permitir a ação de agentes externos como a erosão, as pragas e o fogo, entre outros. Dessa forma, deve existir uma correlação entre a qualidade da paisagem e o risco de incêndios florestais.

Os objetivos deste trabalho são:

- Desenvolver uma metodologia de avaliação da paisagem, utilizando métodos de valoração da qualidade e da fragilidade da paisagem, baseado apenas em mapas descritivos de uma região.

- Comparar os resultados obtidos com o mapa de risco de incêndios florestais existente para essa mesma área.

- Verificar a correlação entre essas duas variáveis (qualidade da paisagem/risco de incêndio).

\section{MATERIAL E MÉTODOS}

\section{Caracterização da área de estudo}

A área estudada foi a Fazenda Brejão, de propriedade da Empresa Vallourec \& Mannesmann, localizada em Brasilândia, na região noroeste do estado de Minas Gerais (Figura 1), cujo mapa é apresentado na figura 2 . Suas coordenadas são $17^{\circ} 02^{\prime}$ de latitude sul e $45^{\circ} 50^{\prime}$ de longitude Oeste, a uma altitude de $575 \mathrm{~m}$.

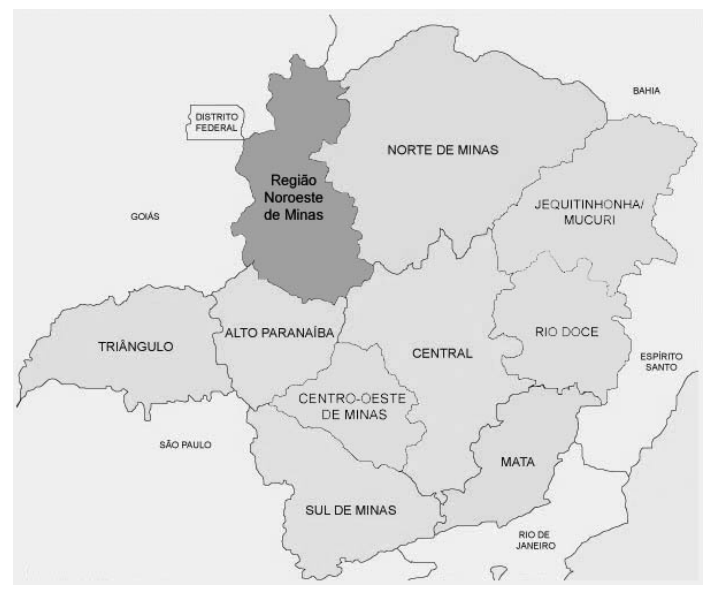

Figura 1. Região noroeste do estado de Minas Gerais.

Figure 1. Nortwest region of the Minas Gerais state. 


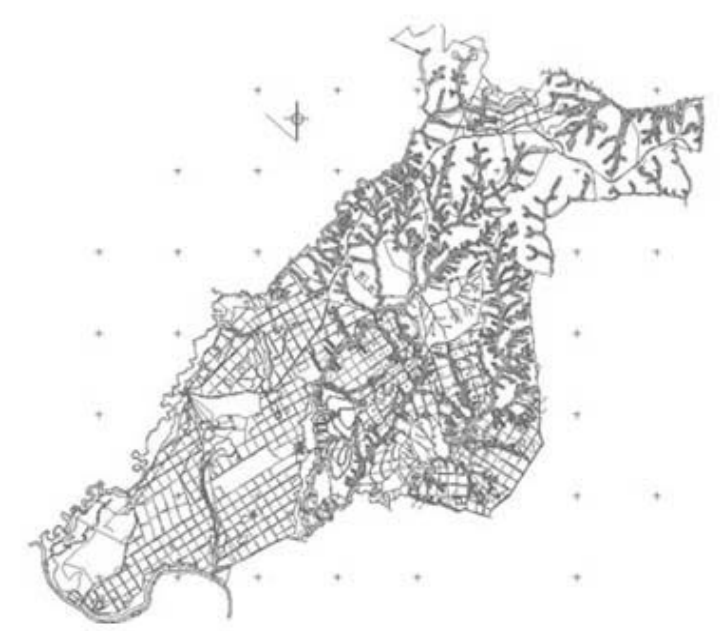

Figura 2. Planta da Fazenda Brejão.

Figure 2. Brejão Farm Map.

O principal uso dessa área é o reflorestamento, existindo também área com vegetação nativa, área destinada a pesquisa e pastagem, como mostra a figura 3.

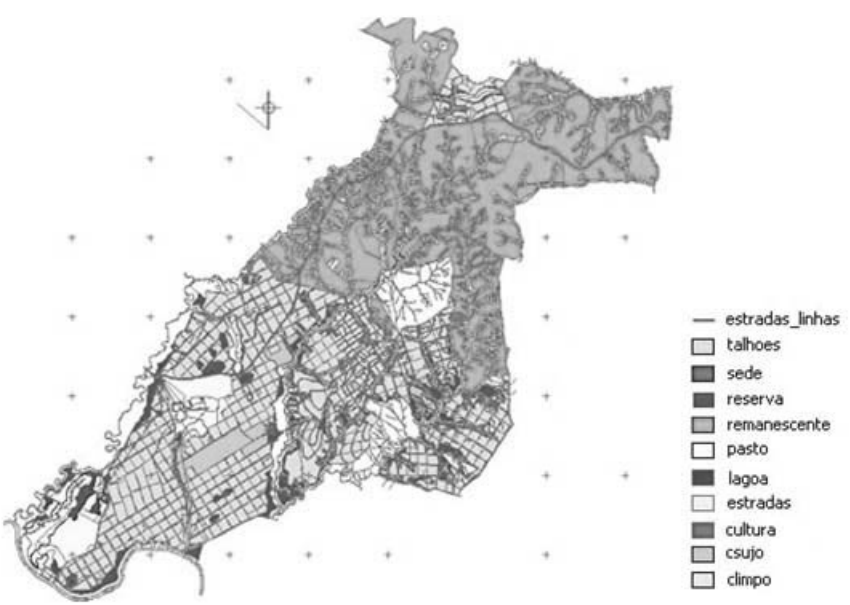

Figura 3. Uso do solo da Fazenda Brejão.

Figure 3. Land use in the Brejão Farm.

\section{Informações sobre o clima e solos}

O clima da região é do tipo Aw, segundo a classificação de Köppen (TREWARTHA; HORN, 1980), caracterizado como clima tropical com inverno seco. A precipitação média anual é de 1441,5 mm, com umidade relativa média do ar de $70,1 \%$.

Os solos predominantes encontrados na área são do tipo Cambissolo, Latossolo VermelhoAmarelo e Latossolo Vermelho-Escuro. A formação vegetal da área é de cerrado senso estrito, com manchas de campo cerrado.

\section{Processo metodológico}

O processo metodológico foi baseado nos métodos indiretos que estabelecem, conforme Pires (1993), que a valoração é realizada através da desagregação da paisagem e da análise de seus 
componentes (elementos da paisagem), de acordo com diferentes juízos de valor e segundo critérios de pontuação e classificação estabelecidos por especialistas.

A aplicação do método envolveu os seguintes passos:

a) Foram confeccionados mapas da cobertura vegetal da área de estudo, utilizando-se o programa ArcGis 8.1, com os dados obtidos pela empresa.

b) A área foi dividida em 24 unidades de área de 5 x $5 \mathrm{~km}$, identificadas por 1D, 1E, 1F, 1G, 2D, 2E, $2 \mathrm{~F}, 2 \mathrm{G}, 3 \mathrm{~B}, 3 \mathrm{C}, 3 \mathrm{D}, 3 \mathrm{E}, 3 \mathrm{~F}, 4 \mathrm{~B}, 4 \mathrm{C}, 4 \mathrm{D}, 4 \mathrm{E}, 5 \mathrm{~A}, 5 \mathrm{~B}, 5 \mathrm{C}, 5 \mathrm{E}, 6 \mathrm{~A}, 6 \mathrm{~B}, 6 \mathrm{C}$, representados na figura 4 pelas quadrículas maiores.

c) Cada unidade de área foi subdividida em 100 subáreas, representadas na figura 4 pelas quadrículas menores. $\mathrm{O}$ objetivo principal dessa divisão foi facilitar a avaliação dos elementos constituintes da paisagem existente em cada unidade de área, ou seja, relacionar em percentagem a presença de cada elemento paisagístico dentro da unidade de área (cada subárea corresponde a $1 \%$ da referida unidade de área).

d) A pontuação de cada unidade de área depende da presença dos componentes paisagísticos existentes e da percentagem de ocupação de cada um deles dentro da unidade estudada.

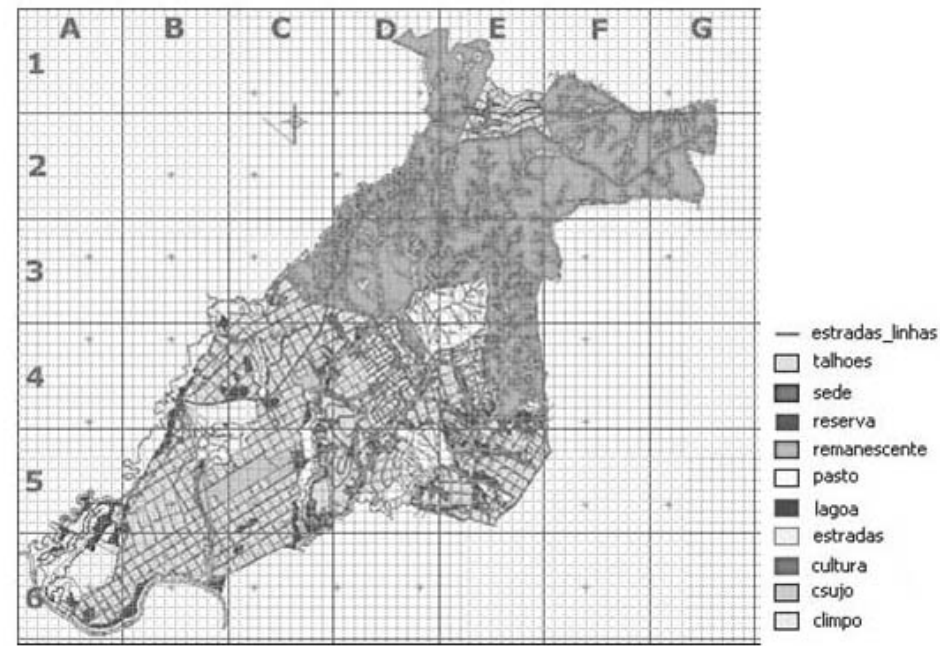

Figura 4. Divisão da Fazenda Brejão em unidades de área.

Figure 4. Division of the Brejão Farm in units of area.

Foram atribuídos pesos para a qualidade e a fragilidade da paisagem. As valorações estão representadas nas tabelas 1 e 2 .

Tabela 1. Valoração da qualidade da paisagem.

Table 1. Valuation of the landscape quality.

\begin{tabular}{llc}
\hline Componente & & Pontuação \\
\hline Cobertura Vegetal & Vegetação natural & 4 \\
& APPs & 4 \\
& Remanescente de vegetação natural & 4 \\
& Vegetação alterada & 3 \\
& Área de pesquisa & 3 \\
& Reflorestamento & 2 \\
& Cultura & 2 \\
& Pasto & 2 \\
\hline Água & Rios & 4 \\
& Lagos & 4 \\
& Represas & 3 \\
\hline
\end{tabular}

FLORESTA, Curitiba, PR, v. 38, n. 1, jan./mar. 2008. 
Tabela 2. Valoração da fragilidade da paisagem.

Table 2. Valuation of the landscape fragility.

\begin{tabular}{llc}
\hline Componente & & Pontuação \\
\hline Infra-estrutura & Carvoaria & 0,30 \\
& Estrada & 0,20 \\
& Rede elétrica & 0,20 \\
& Edificações & 0,15 \\
& Cerca & 0,04 \\
& Aceiro & 0,01 \\
\hline
\end{tabular}

\section{Cálculo da qualidade da paisagem para cada unidade de área}

Tomando como exemplo a unidade de área 1-A, supondo-se que todas as subáreas fossem ocupadas pelo elemento paisagístico "vegetação natural", a pontuação correspondente à "vegetação natural" seria 4; logo, a unidade de área 1-A receberia nota "4". Se esse mesmo quadrante fosse ocupado pelo elemento "vegetação natural" em apenas 50 subunidades e se não houvesse mais nenhum outro elemento paisagístico, significaria dizer que $50 \%$ da área possui "vegetação natural", e a nota correspondente à unidade de área 1-A seria: "vegetação natural" = 4 pontos x 0,5 (50\% de ocupação apenas) $=\mathbf{2}$ pontos.

Para a unidade de área 1-A com 50 subáreas ocupadas por "vegetação natural”, 20 subáreas ocupadas por "culturas" e 30 subáreas ocupadas por "pasto", a nota para o quadrante seria:

"vegetação natural" $=4 \times 0,5(50 \%$ da unidade de área $)=\mathbf{2}$

"culturas" $=2$ × $0,2(20 \%$ da unidade de área $)=\mathbf{0 , 4}$

"pasto" $=2$ x $0,3(30 \%$ da unidade de área $)=\mathbf{0 , 6}$

TOTAL $=\mathbf{3}$

Se na mesma unidade existir uma estrada, cercas e rede elétrica, elementos de origem antrópica que alteram a condição original do ambiente existente e, por isso mesmo, tidos (neste trabalho) como "redutores" da qualidade da paisagem, a nota para a unidade de área 1-A seria:

"cercas" $=-0,05$

"estradas" $=-0,2$

"rede elétrica" $=-0,2$

3 (do TOTAL) - 0,45 (soma dos elementos antrópicos) $=2,55$.

Em resumo:

NOTA $=\Sigma$ de "Valoração da qualidade" $-\Sigma$ de "Valoração da fragilidade" área.

Seguindo-se esse mesmo procedimento, foram calculadas as notas para todas as 24 unidades de

\section{Classificação de cada unidade de área}

Com todos os valores encontrados nas quadriculas, foi feita a sua distribuição, estabelecendo-se classes de valores. Cada unidade de área, em função da nota obtida, foi classificada em classes de qualidade da paisagem. As classes foram: ruim, baixa, média, boa e alta (Tabela 3). Com esses valores, foi confeccionado um mapa com as classes da qualidade da paisagem da área em estudo.

\section{Comparação com o índice de risco de incêndios}

O mapa de qualidade da paisagem foi então comparado com o mapa de risco de incêndios florestais desenvolvido para a área de estudo por Soares; Batista; Oliveira (2003). 
Tabela 3. Classes de Qualidade da Paisagem.

Table 3. Landscape quality classes.

\begin{tabular}{lc}
\hline Classes & Pontuação Total \\
\hline Ruim & $<0,952$ \\
Baixa & $0,953-1,904$ \\
Média & $1,905-2,856$ \\
Boa & $2,857-3,808$ \\
Alta & $>3,809$ \\
\hline
\end{tabular}

\section{RESULTADOS E DISCUSSÃO}

A partir dos valores de pontuação obtidos para as 24 unidades de área, foi gerado um mapa com as classes de qualidade da paisagem (Figura 5). Esse mapa reflete a qualidade da paisagem segundo os critérios adotados no método. Pode-se observar, no mapa, que 20,83\% das unidades de área foram classificadas como ruim, 16,67\% como baixa, 12,50\% como média, 16,67\% como boa e 33\% como alta. De uma forma geral, os elementos que pesam favoravelmente para a obtenção de uma nota alta apresentam uma maior percentagem de ocupação dos elementos indicadores de qualidade da paisagem, havendo uma pequena presença ou ausência dos indicadores de fragilidade da paisagem (que influenciam negativamente na valoração paisagística). A presença de elementos que possuem maior peso na qualidade da paisagem em uma grande porcentagem da unidade de área contribui para que ela atinja uma classe alta. Se a presença desses elementos estiver em uma porcentagem pequena, a unidade de área irá ser classificada como ruim.

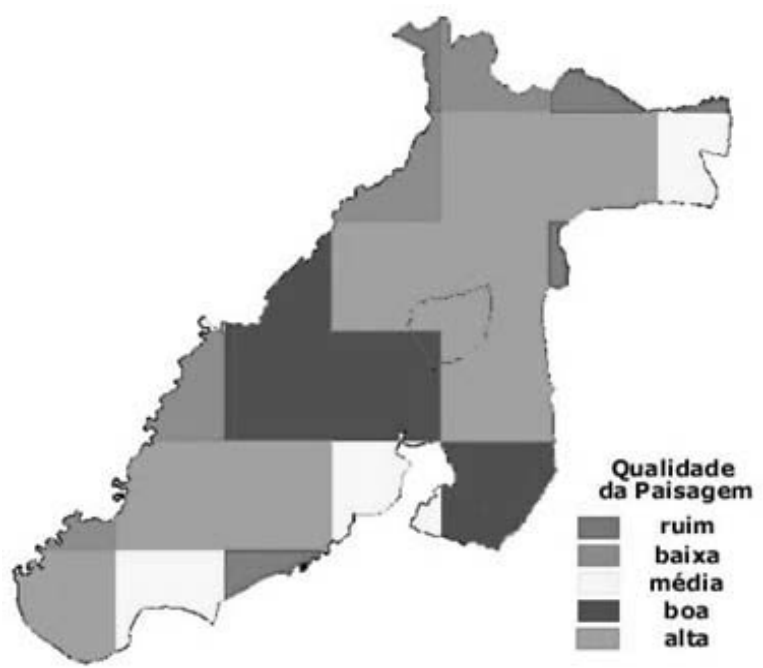

Figura 5. Qualidade da paisagem.

Figure 5. Landscape quality.

O mapa de zoneamento de risco de incêndios florestais com base na vegetação, desenvolvido para a Empresa Vallourec \& Mannesmann, está representado na figura 6.

Comparando as figuras 5 e 6, pode-se observar que na porção norte e oeste do mapa existe uma boa relação entre a qualidade da paisagem e o risco de incêndios florestais, associando classes de qualidade da paisagem ruim e baixa com risco de incêndios muito alto e extremo. Na porção sudeste do mapa, pode-se observar também boa correlação entre as classes de qualidade da paisagem boa e alta com risco muito baixo e baixo. Isso indica que os componentes analisados para valorar a qualidade da paisagem podem ser os mesmos para classificar o risco de incêndios, pelo menos nas classes extremas (altas e baixas). Geralmente, os valores medianos de paisagem não são bem definidos quando se utiliza o método indireto (através de mapas). Segundo Oliveira (2003), quando se complementa a análise indireta com a direta (in loco), muitos dos valores médios passam para a classe alta e outros passam para a classe baixa. 


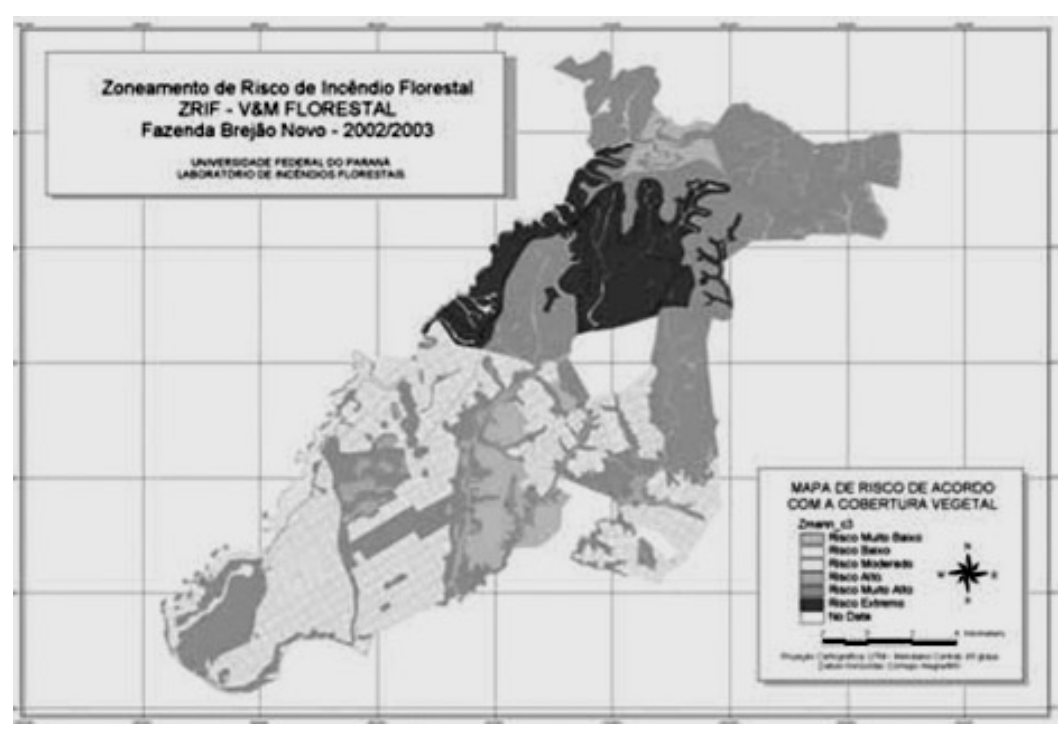

Figura 6. Mapa de risco de incêndios de acordo com a cobertura vegetal.

Figure 6. Forest fire risk map.

No entanto, existem áreas na parte central do mapa em que essas correlações não foram confirmadas. Acredita-se que a inexistência de correlação entre a alta qualidade da paisagem e o baixo risco de incêndios observado em algumas sub-unidades da área estudada esteja relacionada com os seguintes fatores:

a) A área de estudo está inserida em uma região de cerrado brasileiro, bioma que apresenta cinco fisionomias distintas. $\mathrm{O}$ fogo é um dos fatores principais de formação do cerrado, caracterizando a paisagem e sendo responsável pela sua estratificação. Dessa forma, no cerrado podem existir tanto ambientes com alta qualidade paisagística e baixo risco de incêndios quanto regiões com alta qualidade paisagística e alto risco de incêndios.

b) O método apresentado não distinguiu as fisionomias da vegetação nativa, utilizando, da mesma forma, pesos para a valoração das diversas sub-unidades onde esta era identificada.

c) Além disso, foram utilizados os mesmos pesos para a valoração das áreas com vegetação nativa e floresta plantada.

A realização de incursões em campo ou a utilização de fotografias da área de estudo poderiam ser úteis para o refinamento da valoração, possibilitando o estabelecimento de correlações mais apuradas entre a qualidade da paisagem e o risco de incêndios.

\section{CONCLUSÕES}

Pelos resultados obtidos, verifica-se que existe uma boa correlação entre a qualidade da paisagem e o risco de incêndios florestais, sugerindo que a valoração da qualidade da paisagem pode ser uma ferramenta importante para o refinamento e elaboração de mapas de zoneamento de risco de incêndios.

O presente trabalho foi realizado com base apenas no mapa de cobertura vegetal e ocupação do solo da área. Em função disso, as tabelas de valoração da qualidade e da fragilidade da paisagem podem apresentar deficiências que acabam influenciando os resultados.

O método adotado para a realização do trabalho parece ser bastante promissor, necessitando de ajustes e novos testes para a comprovação da sua eficiência.

Como recomendação para futuros trabalhos adotando esta metodologia, sugere-se a inclusão de trabalhos de campo e a utilização de fotografias da região, que poderiam melhorar sensivelmente a qualidade da avaliação. 


\section{REFERÊNCIAS}

AGUILO, M. Guia para la elaboración de estudios del medio físico: contenido y metodología. Madrid: CEOTMA. 1984.

ALONSO, M.; AGUILO, M.; RAMOS, A. Directrices Técnicas para la estimación de impactos. Madrid: E.T.S.I.M. 1983.

ALVAREZ-ALFONSO, R. M. Estúdio y valoracion del paisaje: territorio de Valderejo. 137p. Monografia (Magister em urbanismo y ordenacion del território) - Universidad de Cantábria, Santander, 1990.

BIONDI, D. Fundamentos da paisagem no tratamento ambiental de rodovias. In: SIMPÓSIO NACIONAL RECUPERAÇÃO DE ÁREAS DEGRADADAS, 4., Blumenau. Anais... Blumenau : FURB, 2000. v. 2. p. 10-25.

BIONDI, D.; LEAL, C. T. Análise da Capacidade Paisagística do Parque Estadual de Vila Velha - PR. In: CONGRESSO BRASILEIRO DE UNIDADES DE CONSERVAÇÃO, 3, 2002, Fortaleza, CE. Anais do... Fortaleza: Rede Nacional Pró- Unidades de Conservação, 2002. p. 359-367.

BOLÓS, M.; CAPDEVILA, M. Manual de ciencia del paisaje: teoría, métodos e aplicaciones. Barcelona: Masson, 1992. 193 p.

BROWN, A. A.; DAVIS, K. P. Forest fire: control and use. 2. ed. New York: McGraw-Hill, 1973. 686 p.

CANTERAS JORDANA, J. C. Curso de Introducción al Paisage: metodologias de valoración. Curitiba: Universidade Federal do Paraná / Universidade de Cantábria, 1992. 60 p. Apostila.

CASTAÑEDA, A. Zonificación para el manejo de incendios en plantaciones forestales en Colombia. Boletin de Proteccion Forestal, Colômbia, n. 2, p. 38-46, abr. 1997.

CHENEY, N. P. Predicting fire behavior with fire danger tables. Australian Forestry, Queen Victoria, AU, v. 32. n. 2, p. 71-79, 1968.

ESCRIBANO, M. M.; FRUTOS, M.; IGLESIAS, E.; MATAIX, C.; TORRECILLA, I.. EI paisage. Madrid: E.T.S.I. Montes, 1989, 107 p.

GONZÁLEZ BERNALDEZ, F. Ecologia y Paisaje. Madrid: Blume, 1981.

HARDT, L. P. A. Subsídios à gestão da qualidade da paisagem urbana: aplicação a Curitiba - PR. 323p. Dissertação (Mestrado em Ciências Florestais) - Setor de Ciências Agrárias, Universidade Federal do Paraná, Curitiba, 2000.

MACEDO, W.; SARDINHA, A. M. Fogos florestais: $1^{\circ}$ volume. [S.1.]: Universidade de Trás-os-Montes e Alto Douro, $1985,430 \mathrm{p}$.

MARENZI, R. C. Estudo da valoração da paisagem e preferências paisagísticas no município da Penha-SC. 119p. Dissertação (Mestrado em Ciências Florestais) - Setor de Ciências Agrárias, Universidade Federal do Paraná, Curitiba, 1996.

OLIVEIRA, D. S. Zoneamento de risco de incêndios em povoamentos florestais no norte de Santa Catarina. 113p. Dissertação (Mestrado em Ciências Florestais) - Setor de Ciências Agrárias, Universidade Federal do Paraná, Curitiba, 2002.

PIRES, P. S. Avaliação da qualidade visual da paisagem na região carbonífera de Criciúma-SC. 96 p. Dissertação (mestrado) - Setor de Ciências Agrárias, Universidade Federal do Paraná, Curitiba, 1993.

PYNE, S. J. Wildland fire - Fire management in the United States. New York: Wiley \& Sons, 1984. $769 \mathrm{p}$. 
ROCHA, C. H. Ecologia da Paisagem e Manejo Sustentável em Bacias Hidrográficas: Estudo do Rio São Jorge nos Campos Gerais do Paraná. 176 p. Dissertação (Mestrado em Ciências do Solo) - Setor de Ciências Agrárias, Universidade Federal do Paraná, Curitiba, 1995.

SCHROEDER, M. J.; BUCK, C. C. Fire weather. Washington, DC: USDA Forest Service, 1970. 229 p. (Agriculture Handbook 360).

SOARES, R. V. Determinação de um índice de perigo de incêndio para a região centro paranaense, Brasil. 72p. Dissertaçăo (Mestrado) - Instituto Interamericano de Cięncias Agrícolas da OEA. Departamento de Cięncias Florestais/Centro Tropical de Ensino e Investigação, Turrialba, CR, 1972 b.

SOARES, R. V. Incêndios Florestais: controle e uso do fogo. Curitiba: Fundação de Pesquisas Florestais do Paraná, 1985. 213 p.

SOARES, R. V. Índices de perigo de incêndio. Floresta, Curitiba, v. 3, n. 3, p. 19-40, 1972a.

SOARES, R. V.; BATISTA, A. C.; OLIVEIRA, D. S. Zoneamento de Risco de Incêndios Florestais para a Fazenda Brejão. Curitiba, FUPEF-Vallourec \& Mannesmann Florestal, 2003. 28 p. Relatório Técnico.

TREWARTHA, G. T.; HORN, L. H. Köppen's classification of climates. In: An introduction to climate. New York: McGraw-Hill, 1980. p. 397-403. 